\title{
The Submission of Manuscripts
}

Legal Studies has now adopted ScholarOne Manuscripts, for online manuscript submission and peer review. The new system brings with it a whole host of benefits including:

- Quick and easy submission

- Administration centralised and reduced

- Significan decrease in peer review times

From now on all submissions to the journal must be submitted online at http:// mc.manuscriptcentral.com/lest. Full instructions and support are available on the site and a user ID and password can be obtained on the first visit. If you require assistance then click the Get Help Now link which appears at the top right corner of every ScholarOne Manuscripts page. If you cannot submit online, please contact John Pearson in the Editorial Office (john.pearson@manchester.ac.uk). Legal Studies welcomes submissions of no more than 10,000 words exclusive of footnotes. Footnotes should not be excessive in length or in number. The editors reserve the right to request that authors reduce footnote text in advance of peer review and/or publication. Decisions on manuscripts will normally be made within ten weeks.

In submitting manuscripts authors should observe the following:

(i) Contributions should be word processed, double spaced and with a left hand margin of at least $1 \frac{1}{2}$ inches.

(ii) All contributions should be accompanied by a short abstract.

(iii) Footnotes should appear on the same page as the relevant text, and be indicated by Arabic numerals.

(iv) Internal cross referencing should be to footnotes only (not pages).

(v) References to statutes and cases should follow the style of Halsbury's Laws of England, 4th edition. The publishers are unable to check the accuracy of references and the onus of accuracy falls on the author.

Corrections and amendments of contributions at proof stage are very expensive. Authors are asked to make sure their typescript is carefully checked and finalised particularly with regard to internal cross referencing and the citation of references. Afterthoughts cannot be incorporated on proofs.

Legal Studies uses Author Services which enables authors to track their article - once it has been accepted - through the production process to publication online and in print. Authors can check the status of their articles online and choose to receive automated e-mails at key stages of production so they do not need to contact the production editor to check on progress. The author will receive an e-mail with a unique link that enables them to register and have their article automatically added to the system. Please ensure that a complete e-mail address is provided when submitting the manuscript. Visit www. blackwellpublishing.com/bauthor for more details on online production tracking and for a wealth of resources including FAQs and tips on article preparation, submission and more.

Contributors of articles will be provided with 24 offprints of their contributions and a PDF offprint, subject to terms and conditions of use.

\section{Copyright Transfer Agreement (CTA)}

If your paper is accepted, the author identified as the formal corresponding author for the paper will receive an email prompting them to login into Author Services; where via the Wiley Author Licensing Service (WALS) they will be able to complete the license agreement on behalf of all authors on the paper. 